\title{
Frequencies of Seed Infection and Transmission to Seedlings by Potato Spindle Tuber Viroid (A Pospiviroid) in Tomato
}

\author{
Simmons HE*, Ruchti TB and Munkvold GP
}

Department of Plant Pathology and Microbiology and Seed Science Center, lowa State University, Ames, IA, USA

\begin{abstract}
Potato spindle tuber viroid (PSTVd) is an emerging pathogen that primarily affects members of the Solanaceae. The distribution of this pathogen is expanding rapidly with several countries reporting new infections in recent years. This pathogen is of phytosanitary concern because infected seed is thought to be one of the factors contributing to the spread of this disease. Thus we developed a qRT-PCR method to determine the seed infection frequency of PSTVd in tomato, as well as a RT-PCR method to determine the frequency of transmission of this pathogen to tomato seedlings. Infection frequency of PSTVd in tomato seeds from infected plants (cv. 'Beefsteak') ranged from 62.3-69\% and frequency of PSTVd transmission to tomato seedlings was $50.9 \%$. Germination of the infected seed was significantly lower (53\%) than the parent seed (98\%), and we also determined that viroid titers in the infected seeds were significantly lower (average $173 \mathrm{ng} / \mu \mathrm{l}$ ) than in the infected seedlings $(785 \mathrm{ng} / \mu \mathrm{l})$. Interestingly $\sim 60 \%$ of the infected seedlings did not display any observable symptoms of PSTVd until the second or third week; however, plants that were grown to maturity developed severe symptoms, suggesting that a grow-out assay might not be an accurate method for detection of this pathogen.
\end{abstract}

Keywords: Potato spindle tuber viroid; Seed transmission; Phytosanitary

\section{Introduction}

Tomatoes are one of the most extensively eaten vegetables worldwide and according to the Food and Agricultural Organization 4,803,680 tons of tomatoes (Solanum lycopersicum) were produced globally in 2012, with tomatoes accounting for $\$ 2$ billion of the produce sold annually in the United States [1-3]. However, crop pathogens, and viroid pathogens in particular, have the potential to create devastating losses in this industry, and a pest risk analysis assessing the economic impact of a viroid (Potato Spindle Tuber Viroid (PSTVd)) epidemic on tomatoes in the European Union determined that such an occurrence would result in a financial loss of $€ 5.7$ million [4].

Viroids are small infectious agents composed of a circular single strand of RNA, approximately 245 to $400 \mathrm{nt}$ long. PSTVd is member of the Pospiviroidae (one of the two viroid families) which are rod-like, replicate in the nucleus and are composed of five regions consisting of two terminal ends, as well as a central, pathogenicity, and variable region $[5,6]$. They do not code for any proteins and are unable to replicate without the aid of a host [7]. Likewise, as they do not encode any movement proteins; they rely on host movement factors to move, via the phloem, throughout the plant [8]. It is thought that viroid functions are facilitated through both structural and sequence signals, and multiple structural regions may be implicated in pathogenicity $[9,10]$.

Although potato is the main host for this viroid, it has since emerged in other hosts (including tomato), and the viroid is capable of replicating within 160 species of the Solanaceae [6,11]. In addition, symptomless PSTVd infection has been detected in Cape gooseberry, pepino, and avocado, and symptomless hosts are believed to have the potential to contribute to the spread of this pathogen to susceptible hosts $[6,9]$.

In tomatoes, minor PSTVd infection causes reduced growth and chlorosis, and severe infection causes stunted growth, brittle leaves, and fruit and flower inhibition depending on the viroid strain [6].
PSTVd can be transmitted easily by leaves touching each other or via fingertips, or by reusing tools that have come into contact with an infected plant $[12,13]$. PSTVd transmission by the aphid Myzus persicae (Sulz.) has been demonstrated in the presence of Potato leafroll virions, presumably by encapsidation within the Potato leafroll virus particles [14,15]. In addition, in vivo encapsidation of PSTVd by Velvet tobacco mottle virus particles has also been shown to have occurred in Nicotiana clevelandii [16]. Systemic PSTVd infection of plants that occurred as a result of being pollinated with diseased pollen has also been reported [17].

Seed transmission rates of $0-100 \%$ have been reported for PSTVd in potato, and similarly variable rates have been reported in tomato [17-20]. In tomato it was reported that seed harvested when only the male parent was infected resulted in PSTVd being transmitted to $9 \%$ of the seedlings, and when the female parent was infected PSTVd was transmitted to $6 \%$ of the seedlings. In the same study, it was determined that the transmission rate increased to $11 \%$ when both the parents were infected [20]. Others have reported a lack of seed to seedling infection; for example, no viroid was detected in seedlings (tested at 8,16 and 27 week stage) grown from infected pepper or tomato seeds [21]. Given the variability in reported transmission rates combined with the high probability of transmission occurring due to contact it is extremely important to evaluate and quantify the risk of seed transmission.

Infected seed may be a contributing factor in the spread of this

${ }^{*}$ Corresponding author: Simmons $\mathrm{HE}$, Department of Plant Pathology and Microbiology and Seed Science Center, lowa State University, Ames, IA, USA, Tel: +1 515294 3724; Fax: +1 515294 9357; E-mail: hsimmons@iastate.edu

Received February 24, 2015; Accepted June 18, 2015; Published June 24, 2015 Citation: Simmons HE, Ruchti TB, Munkvold GP (2015) Frequencies of Seed Infection and Transmission to Seedlings by Potato Spindle Tuber Viroid (A Pospiviroid) in Tomato. J Plant Pathol Microb 6: 275. doi:10.4172/21577471.1000275

Copyright: (c) 2015 Simmons HE, et al. This is an open-access article distributed under the terms of the Creative Commons Attribution License, which permits unrestricted use, distribution, and reproduction in any medium, provided the original author and source are credited. 
pathogen, and a recent outbreak in Queensland, Australia is believed to have occurred due to spread from an imported seed lot in a commercial greenhouse [22,23]. PSTVd has been reported in 54 Countries and new countries are reporting infections every year. For example, the Dominican Republic did not have PSTVd in tomato until a recent report of natural infection in 2014 [24,25].

Current phytosanitary requirements are not consistent among countries, and testing seeds for export can be exorbitantly expensive, particularly as some countries require as many as 20,000 seeds to be tested per seed lot. Thus, understanding the frequency of seed infection and transmission to seedlings for this pathogen is vital to informing phytosanitary regulations. To this end we developed a RT-PCR assay to detect PSTVd in tomato seedlings as well as a RT-qPCR assay to detect PSTVd in tomato seeds in order to assess plant-to-seed and seed-toseedling transmission for this economically important pathogen.

\section{Materials and Methods}

\section{Growth chamber experiments}

In order to measure seed transmission, we inoculated fifteen tomato plants (cv. Beefsteak) growing in $25-\mathrm{cm}$ diameter pots in a restricted access growth chamber in the greenhouse at Iowa State University (ISU), under 15 hours of light per day and the temperature held constant at $21^{\circ} \mathrm{C}$. These were inoculated at the third true leaf stage with PSTVd (kindly provided by Robert Owens, Beltsville Agricultural Research Center, Beltsville MD). A $\sim 3 \mathrm{~cm}^{2}$ piece of infected leaf tissue was ground in liquid nitrogen prior to being diluted in a phosphate buffer $\left(0.1 \mathrm{M} \mathrm{Na}{ }^{2} \mathrm{H} / \mathrm{KH}_{2} \mathrm{PO}_{4}\right.$ buffer $)$ in a $1: 3$ ratio by volume. Carborundum powder was dusted on the surface of the third true leaf, and the inoculum was then applied to the leaf surface with a pestle. To confirm infection we tested a leaf from each plant for PSTVd two weeks after inoculation. To avoid cross contamination a new sterile disposable forceps (Trade Winds, Inc., Pleasant Prairie, WI) was used to collect each leaf sample, which was then stored at $-80^{\circ} \mathrm{C}$ prior to extraction. Ripe fruit were collected and stored at $8^{\circ} \mathrm{C}$ prior to seed extraction. A total of 141 tomatoes and 8,041 seeds were collected from the fifteen plants. In order to assess the frequency of seed infection, 350 seeds were individually tested for PSTVd infection, and in order to determine the frequency of transmission to seedlings, 1,620 seeds were planted in individual pots in a restricted access growth chamber in the greenhouse at ISU, under 15 hours of light per day and the temperature held constant at $21^{\circ} \mathrm{C}$. The seedlings were planted with a minimum distance of three inches between seedlings to avoid mechanical transmission of the viroid. Three hundred and fifty seedlings were harvested for testing at the third true leaf stage. Twenty-one of the seedlings that tested positive for PSTVd via RT-PCR were transplanted and grown in order to assess vertical transmission to the next generation of seeds. The plants were grown in a restricted access growth chamber under the same conditions as described above. Only four of these plants survived to produce fruit and from these a total 100 seeds were tested for PSTVd infection via $\mathrm{qPCR}$.

\section{Tomato seed extraction}

Seeds were extracted from the tomatoes by cutting across the mid-section of the tomato using a sterilized scalpel. The scalpel was sterilized with bleach and sprayed with ethanol between each fruit to eliminate cross contamination. The seeds were then scraped from the carpels, and following removal from the fruit were soaked in a $10 \% \mathrm{HCl}$ solution for 30 minutes in order to remove the gelatinous layer from the outside of the seeds. The seeds were then rinsed with water and the slurry was strained using a metal sieve (size 8 round). Both the sieve and collection tray were sterilized between samples. The strained seeds were spread out on a labeled paper towel and allowed to dry overnight in a biosafety cabinet prior to planting or extraction.

\section{Germination testing}

Germination testing was undertaken in the ISU Seed Testing Lab, following the Association of Official Seed Analysts (AOSA)-approved germination testing guidelines. Seeds were placed on moistened rolled towels with $\mathrm{KNO}_{3}$, with four replications of 100 seeds each for a total of 400 seeds per group (infected parents and uninfected parents). These were placed in buckets, covered with plastic wrap, and allowed to germinate for two weeks with a diurnal cycle of eight hours at $30^{\circ} \mathrm{C}$ with light, and 16 hours at $20^{\circ} \mathrm{C}$ in the dark; the towels were remoistened as needed. Germination was assessed twice (day 7 and day 14).

\section{RNA extraction and PCR}

To determine the frequency of PSTVd seed infection, RNA was extracted from the seeds using the Omega E.Z.N.A Plant RNA Kit (Omega bio-tek, GA). A cDNA synthesis was performed according to the manufacturer's specifications using the First Strand Invitrogen kit (Invitrogen, Life Sciences, CA). We performed a RT-qPCR using an Applied Biosystems Real Time Step One Plus machine (Thermo Fisher Scientific, CA) using primers that were developed using Primer Express ${ }^{\oplus}$ Software version 3.0 (Applied Biosystems) forward: 5'-TACCCGGTGGAAACAACTGAA-3' and reverse: 5'-CCCCGGAGCAAGTAAGAT AGAGA-3'. Initial qPCR analysis revealed the presence of primer dimers, and as a result primer optimization was undertaken. Based on these results (data not shown), a 1:1 ratio of nine microliters of each primer per sample was selected for qPCR analysis. The mix contained 25 ul of SYBR green (Life Technologies Corporation, CA), 9 ul of each primer, and 2 microliters of distilled water. The qPCR steps were as follows: a holding step at $95^{\circ} \mathrm{C}$ for ten minutes, $95^{\circ} \mathrm{C}$ for 15 seconds and $60^{\circ} \mathrm{C}$ for one minute for 40 cycles, and melt curve at $95^{\circ} \mathrm{C}$ for 15 seconds, $60^{\circ} \mathrm{C}$ for one minute, and $95^{\circ} \mathrm{C}$ for 15 seconds. The standard curve was produced by creating a dilution series of cDNA stock of PSTVd, and the quality and quantity of DNA was ascertained via a NanoDrop-1000 spectrophotometer (Thermo Scientific, CA).

To determine the frequency of PSTVd transmission to seedlings RNA was extracted from leaf tissue using the E.Z.N.A. Plant RNA Kit according to the manufacturer's protocol (Omega bio-tek, GA). The reaction was prepared using the SuperScript III One-Step RT-PCR with Platinum Taq kit according to the manufacturer's protocol (Invitrogen, Life Sciences, CA) with the exception that we added 10\% DMSO to the mix in order to reduce the amount of secondary structure in the product. The primers used to amplify the target sequence were developed using Primer Express ${ }^{\circledR}$ Software version 3.0 (Applied Biosystems), and are as follows forward: 5'-GCCGAAACAGGGTTTTCACC-3' reverse: 5'-GGTAGTAGCCGA AGCGACAG-3'. To ensure that the product was in fact PSTVd, PCR products from four samples were gel extracted and cleaned using the Zymo DNA Clean \& Concentrator-5 (Zymo Research, CA), and were submitted to the DNA Facility at ISU for sequencing.

\section{Results and Discussion}

PSTVd is a destructive pathogen that can be seed-transmitted at high frequencies and therefore measures need to be taken to prevent spread of the pathogen by seed. We observed extremely high seed infection frequencies, namely; $218(62.3 \%)$ of the 350 seeds that were 
harvested from artificially infected plants tested positive for PSTVd via RT-qPCR, (62-69\%). Of the 100 seeds that were harvested from plants grown from infected seed, 69 (69.0\%) tested positive via RT-qPCR (Table 1). We determined that the difference between the two groups of seeds tested was not statistically significant $\left(\chi^{2}=0.723, p>0.05\right)$. We also observed a high frequency of transmission to seedlings, and 178 (50.9\%) of the 350 seedlings tested positive for PSTVd via RT-PCR (50.85\%), suggesting that infected seed cought contribute to PSTVd dissemination and disease development.

Although seed infection was $62 \%-69 \%$, only $50.9 \%$ of the seedlings were infected. This may be attributable, at least in part, to the low viroid quantities observed in the seeds. We assessed the viroid titers in the infected seeds via qPCR and determined these to be on average $173 \mathrm{ng} / \mu \mathrm{l}$ which was significantly lower than that measured in the infected seedlings $(785 \mathrm{ng} / \mu \mathrm{l})$. In fact we observed viroid titers as low as $0.006 \mathrm{ng} / \mu \mathrm{l}$ in one of the infected seeds; these levels may be too low to successfully initiate seedling infection. This is similar to results previously determined with an RNA virus, Zucchini yellow mosaic virus, where the reported viral titers were lower in the seed (11.3-60 $\mathrm{ng} / \mu \mathrm{l})$ than in the leaf $(2000-3400 \mathrm{ng} / \mu \mathrm{l})$ samples [26]. In addition it is also possible that the lower infection incidence in the seedlings may be due to the lower level of germination for infected versus the healthy seeds. Seeds harvested from PSTVd-infected parents had a germination percentage of $53 \%$ ( $15 \%$ abnormal and $32 \%$ dead). Germination of the parent seed was $98 \%$ with $2 \%$ abnormal. While germination was $53 \%$ for seed from infected plants, only $36.1 \%$ of the seeds planted emerged under growth chamber conditions (Table 1). Germination dropped significantly for seeds from plants infected with PSTVd compared with seeds from healthy plants ( $98 \%$ versus $53 \%$ ). This is similar to previous reports in which low levels of germination (24-48\%) were reported for PSTVd infected tomato seeds [19]. In addition we observed that the number of abnormal seedlings increased quite substantially from 2 to $15 \%$.

The majority ( $\sim 60 \%)$ of the infected seedlings did not display any observable symptoms of PSTVd, and the remainder displayed only mild to moderate symptoms, which included discoloration, as well as mild stunting. However the seedlings that were grown to maturity eventually developed severe symptoms, including leaf curling and severe stunting. In addition $\sim 80 \%$ of the plants exhibited severe fruit and flower inhibition, and only $\sim 20 \%$ of the plants produced any fruit (four out of 21 plants). This is in accord with previous studies that reported the occurrence of symptomless infected seedlings grown from infected tomato and potato seeds, as well as in Scopolia sinensis [20,27]. In the latter study the authors noted that $71 \%$ of the seedlings displayed symptoms, with $66 \%$ displaying symptoms within three to six weeks post emergence; however they observed that $2 \%$ of the seedlings did not display any symptoms until seven to eight weeks post emergence. Completely symptomless PSTVd infection in seedlings grown from infected seed has also been reported and some authors suggest that

\begin{tabular}{|c|c|c|c|c|}
\hline & $\begin{array}{c}\text { Germination } \\
(\mathbf{\%})\end{array}$ & $\begin{array}{c}\text { Emergence } \\
(\mathbf{\%})\end{array}$ & $\begin{array}{c}\text { Transmission } \\
\text { Frequency (\%) }\end{array}$ & $\begin{array}{c}\text { Viroid Titers } \\
\text { (ng/pl) }\end{array}$ \\
\hline Healthy Seeds & 98.0 & $\mathrm{NT}^{*}$ & $\mathrm{NA}^{* *}$ & $\mathrm{NA}$ \\
\hline Infected Seeds & 53.0 & 36.1 & $62.3-69.0$ & 173 \\
\hline Seedlings & NA & NA & $50.9 \%$ & 785 \\
\hline
\end{tabular}

*Not tested.

${ }^{* *}$ Not Applicable

Table 1: Percent germination, percent emergence, transmisson frequency and viroid titers of PSTVd in healthy seeds, seeds harvested from infected plants and seedlings grown from seeds harvested from infected plants. this may be the result of a tolerance mechanism that is developed to the disease in the early embryo stage [17]. However, it is believed that symptomless plants are a potential source of infection, and thus it appears that a grow-out assay would not be a viable detection method for this pathogen $[9,17]$.

It appears that the viroid is located within the seeds and is not simply on the surface of the seed coat, which has implications for determining management strategies for this pathogen. We bleached the seeds and the fact that they were still infected after bleaching supports the possibility that the viroid is within the embryo or secondary metabolites within the seed. However, further research is needed to determine where precisely the viroid is located within the seed.

Although reverse transcriptase PCR was sufficient to detect the viroid in PSTVd infected seedlings, it was not sensitive enough to detect the viroid in all cases of seed infection, presumably as a result of lower titers present in the seed than in the seedling. Thus it appears that phytosanitary testing via qPCR may be a more effective approach than testing via conventional RT-PCR methods. The high seed infection and seedling transmission frequencies determined in this study, combined with the current lack of seed treatments available for this pathogen, underscore the need for a reliable seed detection method for this viroid.

\section{Acknowledgements}

This work was supported by the American Seed Research Foundation (which is an extension of the American Seed Trade Association) Vegetable and Flower Permanent Research Fund.

\section{References}

1. Heuvelink E (2005) Tomatoes. CABI Publishing, Wallingford, Oxfordshire, GBR.

2. FAO (2014) Food and Agriculture Organization of the United Nations FAOSTAT.

3. USDA (2012) United States Department of Agriculture Economic Research Service.

4. Soliman T, Mourits MCM, Oude Lansink AGJM, van der Werf W (2010) Economic impact assessment in pest risk analysis. Crop Prot 29: 517-524.

5. Wiesyk A, Candresse T, Zagorski W, Gora-Sochacka A (2011) Use of randomly mutagenized genomic cDNA banks of potato spindle tuber viroid to screen for viable versions of the viroid genome. J Gen Virol 92: 457-466.

6. Owens RA, Verhoeven J (2009) Potato spindle tuber. in The Plant Health Instructor.

7. Diener TO (2001) The viroid: biological oddity or evolutionary fossil? Adv Virus Res 57: 137-184.

8. Flores R, Hernandez C, de Alba AEM, Daros JA, Di Serio F (2005) Viroids and viroid-host interactions. Annual Review of Phytopathology 43: 117-139.

9. Kovalskaya N, Hammond RW (2014) Molecular biology of viroid-host interactions and disease control strategies. Plant Science 228: 48-60.

10. Sano T, Candresse T, Hammond RW, Diener TO, Owens RA (1992) Identification of Multiple Structural Domains Regulating Viroid Pathogenicity Proc Natl Acad Sci USA 89: 10104-10108.

11. Sastry KS (2013) Seed-borne Plant Virus Diseases. Springer, pp. 10-30.

12. Verhoeven JTJ, Huner L, Marn MV, Plesko IM, Roenhorst JW (2010) Mechanical transmission of Potato spindle tuber viroid between plants of Brugmansia suaveoles, Solanum jasminoides and potatoes and tomatoes. Eur J Plant Pathol 128: 417-421.

13. Manzer F, Merriam D (1961) Field transmission of the potato spindle tuber virus and virus $X$ by cultivating and hilling equipment. American Journal of Potato Research 38: 346-352.

14. Querci M, Owens RA, Bartolini I, Lazarte V, Salazar LF (1997) Evidence fo heterologous encapsidation of potato spindle tuber viroid in particles of potato leafroll virus. J Gen Virol 78: 1207-1211. 
Citation: Simmons HE, Ruchti TB, Munkvold GP (2015) Frequencies of Seed Infection and Transmission to Seedlings by Potato Spindle Tuber Viroid (A Pospiviroid) in Tomato. J Plant Pathol Microb 6: 275. doi:10.4172/2157-7471.1000275

15. Syller J, Marczewski W, Pawłowicz J (1997) Transmission by aphids of potato spindle tuber viroid encapsidated by potato leafroll luteovirus particles. Eur $\mathrm{J}$ Plant Pathol 103: 285-289.

16. Francki RIB, Zaitlin M, Palukaitis P (1986) In vivo encapsidation of potato spindle tuber viroid by velvet tobacco mottle virus particles. Virology 155: 469473.

17. Kryczyński S, Paduch-Cichal E, Skrzeczkowski LJ (1988) Transmission of Three Viroids Through Seed and Pollen of Tomato Plants. Journal of Phytopathology 121: 51-57.

18. Fernow K, Peterson L, Plaisted R (1970) Spindle tuber virus in seeds and pollen of infected potato plants. American Journal of Potato Research 47: 75-80.

19. Benson AP, Singh RP (1964) Seed transmission of potato spindle tuber virus in tomato. Am Potato J 41: 294

20. Singh R (1970) Seed transmission of potato spindle tuber virus in tomato and potato. American Journal of Potato Research 47: 225-227.
21. Lebas BSM (2005) Distribution of Potato spindle tuber viroid in New Zealand glasshouse crops of capsicum and tomato. Australasian Plant Pathology 34: 129-133.

22. Hadidi A (2003) Viroids (Csiro Publishing, Collingworth, Australia).

23. Van Brunschot SL (2014) An outbreak of Potato spindle tuber viroid in tomato is linked to imported seed. Eur J Plant Pathol 139: 1-7.

24. CABI (2014) Crop Protection Compendium. in CAB International Wallingford UK.

25. Ling KS, Li R, Groth-Helms D, Assis FM (2014) First Report of Potato spindle tuber viroid Naturally Infecting Field Tomatoes in the Dominican Republic. Plant Dis 98: 701-703

26. Simmons HE. (2013) Zucchini yellow mosaic virus (ZYMV, Potyvirus): vertical transmission, seed infection and cryptic infections. Virus Res 176: 259-264.

27. Singh R, Finnid R (1973) Seed transmission of potato spindle tuber metavirus through the ovule of Scopolia sinensis. Phytopathology 61: 1034-1035. 